\title{
Leibniz, Spinoza And an Alleged Dilemma FOR RATiOnAlists
}

\author{
JEFFREY MCDONOUGH \\ Harvard University
}

\begin{abstract}
In a stimulating recent paper, "Violations of the Principle of Sufficient Reason (in Leibniz and Spinoza)," Michael Della Rocca argues that rationalists face a daunting dilemma: either abandon the Principle of Sufficient Reason or embrace a radical, Parmenidian-style monism. The present paper argues that neither historical nor contemporary rationalists need be afraid of Della Rocca's dilemma. The second section reconstructs Della Rocca's argument in five steps. The third section argues that Leibniz's treatment of relations undermines one of those steps in particular and thus provides him-as well as contemporary rationalists-with a way out. The fourth section argues that a similar way out is available to Spinoza, and that it's a better way out than either of the two options Della Rocca offers on Spinoza's behalf. The essay concludes with an historically-minded suggestion for those eager to revitalize the once-again popular notion of grounding.
\end{abstract}

\section{Introduction}

In a stimulating recent paper, "Violations of the Principle of Sufficient Reason (in Leibniz and Spinoza)," Michael Della Rocca argues that rationalists face a daunting dilemma: either abandon the Principle of Sufficient Reason (PSR) or embrace a radical, Parmenidian-style monism (20I 2a). The dilemma, as Della Rocca presents it, is rooted in Leibniz's insights concerning relations: as part of his commitment to the Principle of Sufficient Reason, Leibniz insists that relations must be grounded. Thought through carefully, however, that demand, Della Rocca argues, shows that the PSR is inconsistent with any plurality whatsoever. Insofar as they accept both the PSR and a multiplicity of substances, attributes or modes, Leibniz and Spinoza are thus, by Della Rocca's lights, guilty of inconsistency. And the same holds for us. Would-be contemporary rationalists must similarly abandon the Principle of Sufficient Reason or embrace a thoroughgoing monism.

In what follows, I'll argue that neither historical nor contemporary rational- 
ists need be afraid of Della Rocca's "Rationalist Dilemma." Towards that end, the second section reconstructs, in five steps, Della Rocca's argument in support of his Rationalist Dilemma. The third section argues that Leibniz's treatment of relations undermines one of those steps in particular and thus provides him-as well as contemporary rationalists-with a way out of the dilemma. The fourth section argues that a similar way out is available to Spinoza, and that it's a better way out than either of the two options Della Rocca offers on Spinoza's behalf. The essay concludes with an historically-minded suggestion for those eager to revitalize the once-again popular notion of grounding.

\section{A Rationalist Dilemma}

Della Rocca's argument in support of his Rationalist Dilemma might be thought of as proceeding in five main steps. The first step arguably involves nothing more than reformulating the Principle of Sufficient Reason in terms of the currently fashionable notion of a "grounding" relation. ${ }^{\mathrm{I}}$ As Della Rocca puts it:

(I) "If an object $\mathrm{x}$ is in a certain state (or has a certain property or whatever), then there must be some thing or things in which this state is grounded, some thing or things in virtue of which the thing is in that state." (2012a: I 42$)^{2}$

(I) implies that any fact about the world must have a ground, where, as a first pass, one thing may be thought to ground another when the latter holds in virtue of the former. So, for example, it has been maintained that the fact that a ball is redand-round might be grounded in the fact that it is red and the fact that it is round. The fact that a particle is accelerated might be grounded in the fact that it is acted upon by some net positive force. And the fact that an action is wrong might be grounded in the fact that it was performed with malicious intent. ${ }^{3}$ It is sometimes suggested that the grounding relation is, by definition, transitive and irreflexive so that no fact could ground itself. ${ }^{4}$ But if (I) is to be taken as a version of the PSR,

I. The grounding relation has, of course, been the focus of much recent research. For a route into the current debate, see Kit Fine (20I2), Gideon Rosen (20I0), and Jonathan Schaffer (2009).

2. I have indented each of the five steps in my reconstruction of Della Rocca's argument. In those five steps, direct quotation is indicated by the use of quotation marks.

3. All three, now classic, examples are due to Fine (20I $2: 38$ ).

4. For commitment to the transitivity and/or irreflexivity of the grounding relation, see Schaffer (2009: 376), Fine (2010: I00), Dennis Whitcomb (20II). For caution or resistance on this point, see Rosen (20IO, II6), Schaffer (2OI2), and Carrie Jenkins (2OII).

Ergo $\cdot$ vol. 2, no. $15 \cdot 2015$ 
I think it is best understood as allowing that some facts may be self-grounding. ${ }^{5}$ Certainly Leibniz and Spinoza, for example, believe that the PSR is consistent with the thought that, as a necessary being, God's existence is self-explanatory, which in the present context would seem to be equivalent to the claim that God's existence is self-grounded.

Della Rocca's second step is a modest extension of his first. It simply applies the grounding version of the PSR as just formulated to relations. Again, in Della Rocca's own words:

(2) "If objects $\mathrm{x}$ and $\mathrm{y}$ stand in a relation, then there must be some thing or things in which that relation is grounded." (20I 2a: I43)

If the first step rules out ungrounded facts in general, the second step rules out ungrounded relations in particular. If ( $\mathrm{I}$ ) requires that, say, the property of my being six feet tall must be grounded in some thing or things, (2) requires that the relation of my being shorter than Jeremy Lin must similarly be grounded in some thing or things. What exactly is required to ground relations will turn out to be an important issue both for understanding Leibniz's treatment of relations and for assessing the overall force of Della Rocca's argument. We'll return to it below. For now, however, we may take (2) as simply implying that relations, like other facts, cannot be brute.

The third step of Della Rocca's argument is more ambitious. It suggests most crucially that there can be no real relations between distinct subjects. Put conversely, the step may be formulated as follows:

(3) If objects $\mathrm{x}$ and $\mathrm{y}$ stand in a relation $\mathrm{R}$, then $\mathrm{R}$ can only be an ideal, not real, relation. (20 I 2a: I 44-I 45, I47-I48)

While ambitious, Della Rocca argues that (3) follows by dilemma (20I2a: I44$\mathrm{I} 45$ ). From (2) it follows that if $\mathrm{x}$ and $\mathrm{y}$ stand in some relation $\mathrm{R}$, and $\mathrm{x}$ is not identical to $\mathrm{y}$, then either (a) $\mathrm{R}$ must be grounded in $\mathrm{x}$ alone or in $\mathrm{y}$ alone, or (b) $\mathrm{R}$ must be grounded (at least) in $\mathrm{x}$ and $\mathrm{y}$ jointly.

Della Rocca maintains that for a Rationalist (a) is a non-starter. He argues that grounding a relation in $\mathrm{x}$ or $\mathrm{y}$ alone would be arbitrary and thus violate "something like the PSR" (2OI2a: I44). Those who read Leibniz as ascribing to

5. Cf. Fabrice Correia and Benjamin Schnieder, who write, "What is perhaps most puzzling about the rationalist tradition is the steadfast certainty with which the PSR was often accepted. For the PSR in effect denies that there are fundamental facts, i.e. facts that are not grounded by anything else" (2OI 2: 5). 
relational accidents might be tempted to demur. ${ }^{6}$ For one might suppose that if Leibniz thinks that relations themselves may be identified with accidents wholly inhering in individual substances, he may also-as a matter of course-insist that relations may be grounded wholly in individual substances, that is, that for any relation Rxy, R may be grounded entirely in either $\mathrm{x}$ or $\mathrm{y}$. The next section will offer some textual reasons for thinking that Leibniz does not mean to identify relations with relational accidents. Setting that interpretative issue aside for the moment, however, I think that even proponents of the relational accident view might accept at least the spirit of Della Rocca's rejection of (a). For even proponents of the relational accident interpretation might allow that if, for example, we identify being the father of Solomon with a relational accident inhering in solely in David, and being the son of David with a relational accident inhering solely in Solomon, it still couldn't be the case that David is the father of Solomon, or that Solomon is the son of David, without certain things being the case about both David and Solomon. It couldn't be the case, for example, that David is actually the father of Solomon if Solomon had never existed, and, conversely, it couldn't be the case that Solomon is actually the son of David, if David had never existed. The proponent of the relational accident view might still worry-rightfully I think-about what notion of grounding is precisely at stake here, but I think she should allow that relations, for Leibniz, will generally, if not always, be dependent in some way or other upon all the subjects they relate.

Della Rocca further argues that (b) must be ruled out by Leibniz's famous claim that relations can't wear "pants," that is, by his rejection of any accident that "can, at the same time, be in two subjects and has one foot in one, so to speak, and one foot in the other" (G: II, 5 I7/LDC: 327 , see also G: VII, 40I/AG: 339). Since by (2) relations must nonetheless be grounded in something, Della Rocca's Leibniz seeks to ultimately ground them in God's intellect, thus making them ideal rather than real. How to understand Leibniz's "No Pants Doctrine," as well as his views on the relationship between the ideal and the real, will turn out to be crucial both to Della Rocca's interpretation of Leibniz and to the plausibility of his rationalist dilemma. We'll return to them as well in the next section, where it will be argued that Leibniz does not accept the ban on relational pants as Della Rocca understands it, and that, for Leibniz, relations may be, in important senses, both ideal and real at the same time. Before taking up that discussion, however, it should be helpful to fill in the last two steps of Della Rocca's main argument.

The fourth step of Della Rocca's argument attempts to relate (3) to another of Leibniz's most famous doctrines, namely, his Predicate in Subject Principle (PISP). That principle, Della Rocca suggests, may be captured as follows:

6. For sophisticated developments of the relational accident interpretation, see Kenneth Clatterbaugh (I973), Mark Kulstad (I980), Laurence B. McCullough (I996: I72-5) and Dennis Plaisted (2002). See also Della Rocca (2012a: I46-I47). 
(4) "If $\mathrm{x}$ is $\mathrm{F}$, then the state of being $\mathrm{F}$ must be due to, explained by, $\mathrm{x}$ 's nature alone." (20 I 2a: I 53 )

As stated, however, (4) is ambiguous between two different interpretations. On the one hand, if the "due to" and "explained by" in (4) are understood in terms of efficient causes, then (4) will plausibly follow from (3) on the modest assumption that any inter-subject causal relation would have to be a real relation. For (3) rules out real relations, and if any efficient-causal relation between distinct subjects would have to be a real relation, then any of a subject's states that are efficiently-causally generated, will have to be efficiently-causally generated by its own nature. So understood, however, (4) would most closely correspond not to Leibniz's Predicate in Subject Principle but rather to his doctrine of Monadic Spontaneity, according to which each created substance causally unfolds of its own accord without "needing to receive any physical influence" from without "so that it depends only upon God and upon itself in its actions" (G: VI, 289-290, $\mathbb{2} 29 \mathrm{I} / \mathrm{H} 304) .7$

On the other hand, if the "due to" and "explained by" in (4) are understood in terms of essential-formal explanation then (4) will more plausibly correspond to Leibniz's Predicate in Subject Principle. That doctrine asserts that for every genuine (created) subject there exists a complete concept in the divine intellect that contains every predicate true of that subject. The next section will, in effect, argue at length that (4), broadly understood to include explanations of all sorts, does not follow from (3); and that in particular even (metaphysically) ideal relations may have explanations that are (formally, semantically) grounded in both relata. Even if that argument weren't successful, however, I don't think that Leibniz's Predicate in Subject Principle would follow from (3). For one could, of course, deny the existence of real relations, as (3) demands, and still reject, for example, Leibniz's thesis that all propositions are of subject-predicate form, or that there exist complete concepts in the divine intellect. Nor, it might be noted, will the inference work the other way round, that is to say, Leibniz's Predicate in Subject Principle will not entail (3). For, as others have noted, the PISP itself would seem to be consistent with the existence of both predicates of the form "is crossing the Rubicon" and "is being stabbed by Brutus" as well as real relations corresponding to them. ${ }^{8}$

Della Rocca thus fails, I think, to show how the PISP may be derived from Leibniz's views on relations as captured by $(3)$. The want of a deductive connection between (3) and the PISP, however, turns out, I think, not to be very important. For

7. Or at least at a first pass. Leibniz's full understanding of Monadic Spontaneity is complicated by his commitment to the theologically rooted doctrines of creation, conservation and concurrence. For an entry point into Leibniz's understanding of those doctrines and their bearing on his views on monadic agency, see Jeffrey McDonough (2007).

8. For discussion of this point, see especially Kulstad (I980) and J. A. Cover and John O'LearyHawthorne (1999: 58-86). 
Della Rocca's argument for his Rationalist Dilemma draws its real force only from the first three steps sketched above. The dilemma's conclusion asserts that since co-existence would itself have to be a real relation, it follows:

(5) For any $x$ and $y$, such that $x \neq y, x$ and $y$ cannot coexist. (20I 2a: I 57)

It is important to recognize that the variables in $(5)$ are supposed to range over objects as well as over properties, states or modes. The thought with respect to objects is that if two objects were to exist, they would have to stand in a real relation of co-existence, which is ruled out by (3), which in turn is supposed to follow from (2), and ultimately (I), that is, ultimately from the PSR. But nothing turns on $\mathrm{x}$ and $\mathrm{y}$ 's being objects rather than, say, modes. If some one object were to have two modes $F$ and $G$, then $F$ and $G$ would similarly have to stand in a real relation of co-existence, which, again, is supposed to be ultimately ruled out by the Principle of Sufficient Reason. The upshot of $(5)$ therefore is precisely the conclusion Della Rocca wishes to draw, namely, that on pain of inconsistency rationalists who embrace the PSR must also embrace an extreme, Parmenidian-style monism-what I'll call "radical monism"- according to which any kind of plurality is ruled out. ${ }^{9}$

If the overarching argument just sketched were sound, it would have important implications for both traditional and contemporary rationalists. Leibniz, of course, accepts both the PSR and a plurality of substances. If Della Rocca is right, he's guilty of an inconsistency, and indeed of an inconsistency that seems especially embarrassing given that it is alleged to follow from his own insights concerning the grounding of relations. Spinoza might be thought to fare better insofar as he denies that there is a plurality of substances. Nonetheless, on standard interpretations, Spinoza allows that there are a variety of attributes and modes. Indeed, he seems to imply that the one substance enjoys infinitely many attributes, including thought and extension, and that you, me, my dog and my desk are all distinct modes. Insofar as Spinoza countenances a variety of attributes and modes, he would be as guilty of inconsistency as Leibniz. ${ }^{\text {IO }}$ Finally, the Principle of Sufficient Reason has recently enjoyed renewed interest among contemporary philosophers, a renaissance led in no small part by Della Rocca himself (see, especially, Della Rocca 20I0). Della Rocca's rationalist dilemma, however, would seem to up the stakes considerably on accepting the PSR. Although Della Rocca may be willing to

9. Della Rocca himself sums up the import of $(5)$ as follows: "Leibniz's dilemma is this: EITHER give up the claim that there is a multiplicity of objects and that there are states of objects OR give up the claim that relations are grounded" adding that "for those not explicitly committed to the PSR, the dilemma boils down to this: either deny multiplicity or deny that relations are grounded" (2OI 2a: I 57).

Io. As we'll see in the fourth section below, Della Rocca has a more complicated story to tell according to which Spinoza might be thought to be less or even not at all guilty of inconsistency in virtue of his (allegedly) denying the full or even partial reality of attributes and modes. 
follow the Principle of Sufficient Reason wherever it may lead, few contemporary philosophers, I suspect, will be likely to follow if the cost is radical monism. Showing how Leibniz reconciles the PSR with a plurality of substances and states may therefore, as a side-benefit, help to make the PSR more palatable to contemporary philosophers.

\section{Leibniz on Relations and a Way Out}

The crux of Della Rocca's argument in support of his rationalist dilemma is to be found in its third step:

(3) If objects $\mathrm{x}$ and $\mathrm{y}$ stand in a relation $\mathrm{R}$, then $\mathrm{R}$ can only be an ideal, not real, relation. (Della Rocca 20I 2a: I44-I45, I47-I48)

Provided that it's properly understood, Leibniz would, I think, accept (3), and thus grant that there is a sense in which even the relation of co-existence must be an ideal, not real, relation. Properly understood, however, (3) does not entail radical monism. To see how Leibniz can resist the slide from (3) to the denial of all plurality, it should be helpful to begin by teasing apart, and putting into historical context, two different senses in which the PSR might be thought to demand the grounding of relations.

First, the PSR might demand that relational properties be ontologically grounded in intrinsic properties or particular subjects in something like the sense that, say, contemporary physicalists typically insist that mental properties must be ontologically grounded in physical properties or objects. Grounding in this sense was of course an important issue among Leibniz's scholastic predecessors as they disagreed sharply over the ontological foundations of relations. ${ }^{\text {II }}$ Thomas Aquinas, for example, maintains that real relations are a species of accident inhering immediately in (intrinsic) accidents of quantity and quality, and ultimately inhering in particular substances. On Aquinas's theory, my being shorter-than-JeremyLin, for example, is a particular kind of accident that ultimately inheres entirely in my being even though it points, as it were, to another substance, namely, Jeremy Lin. ${ }^{\mathrm{I} 2}$ Reacting in part to moderate realists such as Aquinas, Duns Scotus sought to defend a more robustly realist view of relations. He insists that-at least in some cases-relations may be things (res) that are really distinct from their founda-

I I. For an entry point into discussions of medieval views on relations especially relevant to what follows, see Marilyn Adams (I987: 21 5-276), Massimo Mugnai (I992) and (201 2).

I 2. See, Aquinas (I882- ), Scriptum super libros Sententiarum I, d. 26, q. 2, a.I, ad 3, De potentia Dei q.7, a.8, ad 5; De potentia Dei q.7, a.9, ad 7. For a helpful discussion of Aquinas's views on relations, see especially Mark G. Henninger (I989: I3-39). 
tions. He thus argues, for example, that spatial proximity does not hold in virtue of any two objects or their accidents per se, so that if two objects are proximate, they must be proximate in virtue of a real relation that is really distinct from the related objects and their accidents. ${ }^{\mathrm{I}}{ }^{3}$ Taking Soctus as his primary target, William Ockham in turn characteristically swung in the opposite direction, upholding a less robustly realist view of relations than even Aquinas's. On Ockham's account, relations, like species, are to be identified with connotative mental terms: the relation of, say, a dog's sitting next to a cat, is to be identified with a mental term that primarily signifies either the dog, the cat, or both and connotes that there is nothing between them. ${ }^{14}$ Setting aside special theological cases, Ockham maintains that relations are ontologically ideal and therefore not ontologically real in either Aquinas's modest sense or in Scotus's more robust sense.

Leibniz's views on the ontology of relations have been the subject of much scholarly debate. ${ }^{15}$ It is nonetheless clear that in his mature period Leibniz means to reject the sort of realism one finds in Scotus. On Scotus's picture a real relation would be a kind of mind-independent bridge relating two or more subjects but nonetheless being really distinct from those subjects and their intrinsic accidents. And that, of course, seems to be exactly the sort of picture Leibniz means to rule out with his No Pants Doctrine. Leibniz's opposition to the sort of moderate realism endorsed by Aquinas is, however, less obvious. For Leibniz does sometimes attribute relational predicates to particular substances (e.g., G: IV, 443/L: 308) and one might take such attributions as an indication of his commitment to relational accidents. Furthermore, there are passages that might be read as directly implying Leibniz's commitment to relational accidents, as, for example, when he writes that "The ratio or proportion between two lines $\mathrm{L}$ and $\mathrm{M}$ may be conceived . . a as a ratio of the greater $\mathrm{L}$ to the lesser $\mathrm{M}$, as a ratio of the lesser $\mathrm{M}$ to the greater $\mathrm{L}$. . In the first way of considering them, $\mathrm{L}$ the greater, in the second, $\mathrm{M}$ the lesser, is the subject of that accident which philosophers call 'relation'" (G: VII, 4OI/L: 704). ${ }^{16}$ Nonetheless, even a moderate ontological realism like Aquinas's is, I think, incon-

I3. See, Scotus (I950-) Ordinatio II, d. I, q. 4-5. For helpful discussion of Scotus's views on relations, see especially Adams (I987: 217-222) and Henninger (I989: 68-97).

I4. See, Ockham (I967-I986) Ordinatio I, d.30, q. I. For helpful discussion of Ockham's views on relations, see especially Adams (I987: 21 5-276) and Henninger (I989: I I9-I49).

I 5. See, for example, Cover and O'Leary-Hawthorne (I999: 58-86), Jaakko Hintikka (I972), Hidé Ishiguro (I990), Anja Jauernig (2010), Kulstad (I980), Benson Mates (I986), McCullough (I996), Mugnai (I992; 20I2), Plaisted (2002), Nicholas Rescher (I98I), Bertrand Russell (I900).

I6. For development of this line of interpretation, see especially Kulstad (I980). For criticism of the relational accident view as an interpretation of Leibniz see especially Mugnai (I992; 20I2), and Cover and O'Leary-Hawthorne (I999: 58-86); see also Cover (2004: 99-I08). My own understanding of Leibniz's views on the metaphysics of relations most closely coincides with the view expressed in Mugnai (2OI2), at least insofar as Mugnai interprets Leibniz as identifying relations themselves with mental entities (see 20I 2: 203) and not merely with their non-relational foundations (see 20I 2: 208). 
sistent with Leibniz's repeated insistence that relations are mind-dependent ideal entities, ontologically grounded in the divine intellect much like the eternal truths of reason. Thus, for example, he tells us that "A relation is an accident which is in several subjects and is only a result or supervenes ... if several things are thought of simultaneously: it is a concogitabilitas;" that ". . . relations which join two monads, are not in one monad or the other, . . . but in the mind alone;" and that "there are two things which only the divine understanding can realize: all the eternal truths, and, of the contingent ones, those which are relational" (A: VI.iv.866; G: II, 5 I 7; LH: viii: 6I, reprinted in Mugnai I 992: I $55^{-1}$ 60; see also LH: IV, 7c, Bl. 35v; A: VI.iv.28; G: II, 486; G: II, 438; A: VI.vi.265). Leibniz's steadfast contention that relations are ontologically mind-dependent, ideal entities thus implies that his considered view on the metaphysics of relations is actually closer to Ockham's than to either Aquinas's or Scotus's.

Second, the PSR might demand that relational statements or truths be semantically or truth-makingly grounded, that is, that if a statement of the form "aRb" is true, there must be some basis that grounds its truth. Here as well Scotus's view may serve as a convenient point of reference. With respect to the most relevant class of statements, Scotus maintains that relational statements of the form "aRb" will be true only if there exists an extra-mental relation $\mathrm{R}$ relating $\mathrm{a}$ and $\mathrm{b}$ which is nonetheless really distinct from a and b. For Scotus, we may say that the truth of " $a R b$ " rests on $a, b$, and $R$ and that " $a R b$ " is objectively true because $a, b$, and $\mathrm{R}$ are mind-independent entities (I950-: VIII, IO5 [Ordinatio II, d.I, q. 4-5]). Scotus's view can be usefully contrasted with Peter Auriol's. Auriol maintains that, metaphysically speaking, no two objects can stand in any relation absent a mind's apprehending them. He asserts, for example, that "without apprehension, there is not a greater conformity in act[uality] between two whitenesses than between a whiteness and a blackness" and that "from the nature [ratione] of relation in general, it can be seen that a relation itself exists ... only in objective apprehension" (I952-56: d. 3I). ${ }^{17}$ Thus Auriol-in contrast to Scotus—takes relations to be ontologically mind-dependent. He nonetheless concurs with Scotus's semantics, agreeing that the truth of statements of the form " $a \mathrm{Rb}$ " must rest on $\mathrm{a}, \mathrm{b}$, and $\mathrm{R}$. He therefore boldly defends the view that "aRb" cannot be mind-independently true; that were there (per impossibile) no minds to apprehend a and b, all relational statements of the form " $\mathrm{aRb}$ " would be false or incoherent (Auriol I952-56: d. 30; Adams I987: 250). Ockham, although he shares Auriol's views on the metaphysics of relations, nonetheless rejects Auriol's bold semantic conclusion. In contrast to both Scotus and Auriol, Ockham effectively denies the assumption that the truth of statements of the form " $a \mathrm{Rb}$ " must rest on $\mathrm{a}, \mathrm{b}$, and $\mathrm{R}$. He maintains instead that,

I7. For helpful discussion of Auriol's views on relations, see Henninger (I989: I 50-I73). For a brief overview of Auriol's metaphysics, see Russell Friedman (2009). 
even where $\mathrm{R}$ is itself a mental term, and so itself ontologically mind-dependent, the truth of "aRb" may rest solely on a and b, and thus its truth conditions may be mind-independent (Ockham I967-I986: V, 45 [Reportatio II, q. 2]; Adams I987: 254). Thus on Ockham's view, if there were (per impossibile) no minds to apprehend my dog and my cat, there could be no metaphysical relation holding between them. ${ }^{18}$ Nonetheless, it could still be true, on Ockham's view, that my dog is bigger than my cat. By resisting the unsophisticated semantic view that statements can be objectively true only if each of their terms stands for an extra-mental entity, Ockham is able to maintain that relational statements may be objectively true even if relations themselves are ontologically mind-dependent. ${ }^{19}$

Leibniz's understanding of the semantics of relations is, I think, once again closest to that of Ockham's. His conceptualism about the metaphysics of relations rules out the sort of semantics proposed by Scotus (or, for that matter, by Aquinas). Since relations are not mind-independent entities on Leibniz's view, statements of the form "aRb" can't be true in virtue of the mind-independent existence of a, b, and R. Nor is it plausible to suppose that he adopted a view like Auriol's. For Auriol's position had always been considered an extreme view, and Leibniz follows none of Auriol's careful work designed to make his radical nominalism more palatable (Auriol I952-56: d. 30). Indeed, on the contrary, the very sort of passages cited earlier that made it initially tempting to suppose that Leibniz might hold a metaphysical view like Aquinas's provide convincing evidence that Leibniz means to reject Auriol's semantics. When Leibniz says things like "In my opinion all extrinsic denominations are founded in intrinsic denominations" (LH IV 8, Bl. 6I, reprinted in Mugnai I992: I 55-I60), he suggests quite clearly that there must be a mind-independent basis for the truth of relational statements. The best overall interpretation of Leibniz's position therefore, I think, sees him as following in Ockham's footsteps not just with respect to the metaphysics of relations, but also

I8. From the standpoint of possible world semantics, such counterfactuals-namely those assuming the falsity of an allegedly necessary truth-can be difficult to evaluate, or at least can be difficult to evaluate as being anything other than trivially true. Nonetheless, it is, I think, not at all difficult to grasp the intuitive thought behind counterfactuals such as "if there were no minds (including God's), there would be no relations," and to understand them as being substantive. Rather than seeing Medieval and Early Modern appeals to such counterfactuals as confused or wrong-headed, I'm inclined to see them as providing further (and in some ways better) support for the view-common amongst defenders of the grounding relation - that metaphysics requires a finer-grained notion of modality than has been customarily on offer in the possible world semantics of the past fifty years or so.

I9. Ockham's treatment of relations, I think, nicely parallels his treatment of the metaphysics and semantics of universals. In rough outline, Ockham maintains that species, for example, may generally be identified with mental terms, but that the truth of statements such as "All dogs are mammals" needn't depend on the existence mental terms but rather on the referents of those mental terms. For a discussion of Ockham's views on universals friendly to such an interpretation, see especially Adams (I987: I3-I42). 
with respect to the semantics of relational statements. On such an interpretation, Leibniz would insist that if no mind were to relate my dog to my cat, there would be no metaphysical relation between them, since relations are ontologically minddependent entities. Nonetheless, he would also maintain that even if there were no mind-dependent relations relating my dog and my cat, my dog and my cat themselves might still provide an objective, sufficient basis for the truth of the statement "my dog is lazier, hungrier, and friendlier than my cat." 20

We are now in a better position to see how Leibniz could consistently allow the relation of co-existence to be an ideal, not real, entity, and nonetheless insist that the world objectively contains a plurality of co-existing substances and states. In keeping with his general account of relations, Leibniz could maintain that even the relation of co-existence may be an ideal entity in the sense that it must be (at least partially) ontologically grounded in some apprehending mind. He could allow, for example, that if there is a relation of co-existence holding between my dog and my cat, then that relation must be an ideal entity, ontologically grounded in the divine intellect. Likewise, he could allow that if my dog has two appetites, and those appetites stand in a relation of co-existence, then the relation of co-existence holding between those appetites must also be a mind-dependent entity. But radical monism needn't follow from Leibniz's conceptualist account of the metaphysics of relations. For Leibniz could - and I think would — still insist that the truth of statements about the co-existence of entities has an objective, mind-independent basis. He could thus maintain, for example, that even if no mind were to relate my dog and my cat, the statement "My dog and my cat both exist" would nonetheless be objectively true. Likewise, he could insist that even if no mind were to relate the various appetitive states of my dog, the statement "My dog has a greater appetite for her ball than her bone" would still be objectively true. In short, Leibniz may maintain that relations are typically ontologically ideal entities, while still denying the conclusion that relations must therefore be "not real" in the sense of not being objectively grounded.

One might counter that even if the distinction between ontological and semantic grounding is granted, Leibniz's way out of Della Rocca's dilemma will still stumble on the demands of the PSR. More specifically, it might be objected that Leibniz's account of the truth of relational statements of the form "aRb" commits him to a vicious circle or an infinite regress that is inconsistent with his commitment to rationalism. Thus, Della Rocca, drawing inspiration from Bradley, argues:

20. Leibniz's full semantics is, of course, further complicated by his views on modality and his esoteric view of truth. Those complications may, I think, be bracketed for our present concerns, however, since the key point at issue here is simply Leibniz's mundane conviction that the truth of affirmative, existential propositions, must be (at least partially) semantically grounded in features of the actual world. Furthermore, nothing in Della Rocca's argument draws support from Leibniz's views on modality and truth. For an overview of Leibniz's views on modality, see Robert Adams (I994: 9-I I2). For a helpful introduction to Leibniz's views on the nature of truth itself, see Mates (I986: 84-IO4).

Ergo $\cdot$ vol. 2, no. $15 \cdot 2015$ 
If the relation between $\mathrm{x}$ and $\mathrm{y}$ were a state of $\mathrm{x}$ and $\mathrm{y}$ jointly, then this relation would be determined by, explained by, grounded in, $\mathrm{x}$ and $\mathrm{y}$ together. The 'jointly' and 'together' here are crucial, for these terms indicate that the relation is grounded at least in part in the fact that $\mathrm{x}$ and $\mathrm{y}$ are together, the fact that they co-exist with certain natures, i.e. the fact that they are related somehow. So the relation between $\mathrm{x}$ and $\mathrm{y}$ is grounded in their standing in a certain relation. But this is hardly an illuminating explanatory ground: at best it merely passes the buck to another relation that needs to be explained (and thus threatens to lead to an infinite regress of relations), at worst it is an out-and-out circular explanation. It's not an option for Leibniz (or for a proponent of PSR) to say that the relation is ungrounded or is grounded in other relations which are grounded in other relations and so on ad infinitum. To adopt such a view would be to say that ultimately there is no thing or things in virtue of which $\mathrm{x}$ and $\mathrm{y}$ stand in this relation. This result would violate the plausible grounding principle (2) (and also the PSR). (20I 2a: I48; cf. Bradley I 899: I, Chs. 2-3).

Della Rocca's worry here is, I think, best viewed as a renewed objection to Leibniz's account of the semantics of relations. The thought is that a relational statement of the form "aRb" could be semantically grounded only in either (i) the fact of a and b's co-existing or (ii) some further fact, such as of a and b's existing jointly or together. But (i) would make the fact of their co-existence itself brute, and thus directly violate the PSR, while (ii) would threaten an infinite regress of grounding facts, also plausibly violating the PSR. ${ }^{2 \mathrm{I}}$

In spite of its distinguished Bradleyan heritage, however, I don't think that Leibniz should be much moved by this renewed line of attack. ${ }^{22}$ To see why not, it might be helpful to distinguish between two kinds of facts that might be thought to stand in need of grounding or explanation: (a) the fact that some relation $\mathrm{R}$ exists given that its (primary) relata $\mathrm{x}$ and $\mathrm{y}$ exist; and (b) the fact that $\mathrm{x}$ and $\mathrm{y}$ themselves exist. Leibniz's treatment of relations is directed primarily at facts of sort (a). That is to say, he's chiefly concerned to explain the necessary and sufficient conditions for some relation to exist given that its (primary) relata exist. As we've

2I. One might, of course, insist that an infinite regress of grounds may satisfy the PSR (see, for example, Hume I980: Ch. IX). I agree with Della Rocca, however, that Leibniz at least would demur. It's worth noting nonetheless that contemporary philosophers who insist on the grounding relation's being transitive, asymmetric, and irreflexive, might—somewhat ironically—see such regresses as the only possible way of satisfying the PSR (a conclusion that, as noted above, medieval and early modern philosophers could hope to avoid, most plausibly, by denying irreflexivity). Special thanks are due to Selim Berker for helpful discussion concerning this last point.

22. For a fascinating discussion of Leibniz's early attempts to respond to regress worries such as those later raised by Bradley, see Mugnai (20I0). 
seen, that account would seem to be perfectly consistent with both the ontological and semantic demands of the PSR. But what would he say about facts of sort (b)? Here I think Leibniz should and would insist that the fact that $\mathrm{x}$ and $\mathrm{y}$ both exist is fully explained or grounded if the fact that $\mathrm{x}$ exists is explained or grounded and the fact that $y$ exists is explained or grounded. If one has an explanation of the fact that my dog exists, and one has an explanation for the fact that my cat exists, then ipsis factis one has an explanation for the fact that both my dog and my cat exist. Likewise if one has an explanation of the fact that my dog has a desire for a bone, and one has an explanation for the fact that my dog has a desire for a ball, then ipsis factis one has an explanation for the fact that my dog has a desire for a bone and a desire for a ball. Leibniz's ontology is, of course, an ontology not of facts but of substances and their accidents. He might therefore find Della Rocca's concern to ground facts, rather than substances and their accidents, initially a bit puzzling. Nonetheless Leibniz was famously willing to accommodate the terminology of his interlocutors, and so one can easily imagine him restating his position in terms of facts. What is harder to imagine is his agreeing with the intuition that, say, having explained the fact that one substance exists and the fact that another substance exists, there should remain an additional fact still standing in need of explanation, namely, the fact that both substances exist.

One might object, of course, that Leibniz still owes us an account of the existence of particular substances and accidents that is consistent with the PSR. For all that has been said thus far, that seems fair enough. It could hardly be maintained, however, that Leibniz fails to offer a worked-out and sophisticated account of the grounds of the existence of particular substances and their accidents. While this is not the place to rehearse in detail Leibniz's attempt to steer a middle course between the Scylla of necessitarianism and the Charybdis of brute contingency, it may nonetheless be worthwhile to briefly note how Leibniz's famous efforts in this regard might be framed in terms of the distinction drawn above between ontological and semantic grounding.

Focusing (first) on ontological grounding, we may say that, for Leibniz, (i) the existence of particular modes will be ontologically grounded in the existence of particular created substances, and that (ii) the existence of particular created substances will be ontologically grounded in God, the only uncreated, self-grounded substance. The case (i) of created substances and their modes is entirely straightforward. For if we think of created substances as standing in a relation to their accidents, Leibniz's No Pants Doctrine will be satisfied trivially since the No Pants Doctrine only applies to relations holding between distinct substances, that is to say, it is a ban on real inter-substantial relations, not a ban on intra-substantial relations (e.g., G: II, 5 I7/LDC: 327 ). The case (ii) of divine relations is naturally 
a bit trickier. ${ }^{23}$ Standard Christian doctrine holds that divine creation is creation ex nibilo, that is, literally from nothing. But if creation is literally from nothing (and conservation is a continuous creation) it's not clear that we should think of creation as a relation at all, that is, as an accident that holds between two distinct entities. And, of course, if creation is not really a relation at all, then the No Pants Doctrine will again be satisfied trivially. If creation and its corollaries, however, must be thought of as relations, then it is reasonably clear that Leibniz would have us see them as principled exceptions to the No Pants Doctrine. Indeed, in a letter to Buchard de Volder of January I704, Leibniz states quite explicitly "There is only one case of a substance acting immediately on substance, namely of an infinite substance acting on finite ones, which action consists in continually producing or constituting them" (G: II, 264). ${ }^{24}$ It is worth noting, however, that even if creation is treated as a principled exception to the No Pants Doctrine, it needn't automatically be seen as an exception to the PSR. For in the case of creation it seems plausible to suppose that the relation of, say, God's creating Adam ex nibilo is ontologically grounded in God alone rather than in Adam alone or even in God and Adam together. ${ }^{25}$ While it might seem far-fetched to suppose that my being shorter than Jeremy Lin should involve no ontological contribution on my part, it doesn't seem at all implausible to suppose that my being created by God, even if that is viewed as a real relation, should involve no ontological contribution on my part.

Focusing (second) on semantic grounding, it is, I think, fair to say that the aspects of Leibniz's semantics relevant to the existence of particular substances and accidents are entirely straightforward since none of the complications that arose in connection with the semantics of relations will arise in those cases. ${ }^{26}$ The statement, for example, that "Judas exists" will be objectively true only if Judas exists. The statement "Judas desires gold" will be objectively true only if Judas desires gold. Since substances and their accidents needn't be ideal in any sense for

23. Medieval philosophers, of course, wrestled with a number of difficult problems in connection with divine relations. With respect to the question of whether God is really or only rationally related to creatures, a not uncommon view held that creatures, as dependent beings, are really related to God, while God, as an immutable being, is only rationally related to creatures. For further discussion and a guide some primary texts, see Henninger (I989: 3 I-39).

24. Ockham also famously maintains that real relations-while unsupported by natural reason-can and should be postulated on theological grounds (I967-I986: 306-307 [Ordinatio I, d.3o, q. I]). In particular, Ockham argues that the postulation of real relations is required by the doctrines of the Trinity, the Incarnation, and Transubstantiation. For further discussion, see Adams (1987: 267-276).

25. Medieval philosophers appear to have typically agreed that the relation of creation is not grounded in both creatures and God. For (it seems to me) largely theological reasons, however, they often suggested that the real relation of creation is grounded not in God but rather in created beings. A relatively intuitive basis for this view is to be found the standard theological doctrine of God's absolute immutability. For further discussion, see Henninger (I989: 3 I-39).

26. Again, to keep the discussion focused on our present concerns, I bracket complications that might arise in connection with Leibniz's views on modality and truth. See note 20 above. 
Leibniz, an unsophisticated treatment of the semantic grounds concerning statements about them will do just fine. It may be worth emphasizing, however, that one should be careful not to confuse Leibniz's views on the semantic grounds of existential statements concerning substances and accidents with what are, I think, best viewed as a distinct set of grounds altogether, namely, the teleological or rational grounds for particular existences. For even once the relevant ontological and semantic grounds for particular existences have been identified, one might still ask, for example, "But why does Judas exist?" where the relevant why-question asks not for further metaphysical or semantic grounds, but rather the end, purpose, or reason for Judas's existence. Leibniz's own answer to this further why-question is, of course, that Judas exists because he belongs to the best of all possible worlds, and that God's essential goodness inclines him, without necessitating him, to create the best of all possible worlds and thus to create Judas. The strengths and weaknesses of Leibniz's theodician account of why God creates the actual world and its denizens are, of course, subject to debate. But the success or failure of Leibniz's attempt to identify teleological grounds for the existence of the actual world and its members is not directly at issue here. Our central concern has been whether or not Leibniz's commitment to the ideality of relations and the PSR forces him to embrace a radical monism. And I think it should be clear by now that the answer to that question is "no." For Leibniz can allow that relations, including the relation of co-existence, are ideal insofar as they are metaphysically grounded in the divine intellect, and yet insist that it is nonetheless objectively true that there are infinitely many created substances and accidents.

\section{Three Ways Out for Spinoza?}

Spinoza has less to say than Leibniz about either the Principle of Sufficient Reason or the grounding of relations and relational statements. ${ }^{27}$ Nonetheless, as a Rationalist, he too must at least implicitly confront Della Rocca's dilemma. In the remaining sub-sections, I would like to therefore briefly consider three possible ways in which Spinoza might respond to Della Rocca's dilemma, and suggest that his best way out is to follow Leibniz's lead.

27. The best direct textual support for Spinoza's commitment to the PSR comes from the Ethics. At Erpird2, he writes "For each thing there must be assigned a cause, or reason, both for its existence and for its nonexistence." And at EIp8s2, he writes, "[I]f, in Nature, a certain number of individuals exists, there must be a cause why those individuals, and why neither more nor fewer, exist." For discussion of Spinoza's commitment to the PSR and Rationalism more generally, see Della Rocca (2008b: I-32; 2008a), and Bennett (200I: I70-I 85 ; I984: 29-32). 


\section{I. A First Way Out: Leibniz’s Way}

Spinoza, of course, denies that there is a plurality of substances. Consequently, he has no need to show that the PSR is consistent with the existence of distinct substances. Nonetheless, Spinoza does appear to commitment himself to metaphysical pluralities. At Ipros, for example, he implies that the one substance must have infinitely many attributes, writing:

It is far from absurd to attribute many attributes to one substance. Indeed, nothing in Nature is clearer than that each being must be conceived under some attribute, and the more reality, or being it has, the more it has attributes which express necessity, or eternity, and infinity. And consequently there is also nothing clearer than that a being absolutely infinite must be defined ... a a a being that consists of infinite attributes, each of which expresses a certain eternal and infinite essence.

In addition to the existence of infinitely many attributes, Spinoza also appears to commit himself to the existence of infinitely many modes. Thus, for example, in Ipı6, he asserts that "From the necessity of the divine nature there must follow infinitely many things in infinitely many modes," and offers the following demonstration:

This proposition must be plain to anyone, provided he attends to the fact that the intellect infers from the given definition of any thing a number of properties that really do follow necessarily from it . . . and that it infers more properties the more the definition of the thing expresses reality, that is the more reality the essence of the defined thing involves. But since the divine nature has absolutely infinite attributes ... from its necessity there must follow infinitely many things in infinite modes (i.e., everything which can fall under an infinite attribute).

Taken at face value, Spinoza's texts thus appear to commit him to a plurality of both attributes and modes. Indeed, taken at face value, Spinoza's texts appear to commit him to a truly magnificent variety, an actual infinity of attributes or essences as well as actual infinity of modes or properties.

In addition to such direct textual evidence, many of Spinoza's most central and philosophically significant doctrines also appear to commit him to the existence of a variety of attributes and modes. The thesis of mind-body parallelism, for example, asserts that the "order and connection of ideas is the same as the order and connection of things" (II2p7s). The exact meaning of Spinoza's mind-body parallelism is, of course, open to interpretation. Prima facie, however, it seems to 
presuppose the existence of at least two different attributes and some number of modes falling under them. For it is hard to see how one could possibly have a parallelism without at least two series of parallel entities. Likewise, in his account of knowledge, Spinoza asserts a "third kind" of "intuitive" knowledge that "proceeds from an adequate idea of the formal essence of certain attributes of God to the adequate knowledge of the [NS: formal] essence of things" (IIp4Os2). Here again there is surely room for competing interpretations of what exactly Spinoza thinks intuitive knowledge amounts to. But any plausible interpretation would seem to presuppose Spinoza's commitment to the existence of a plurality of attributes and things or modes. For without such a presumption it is again hard to see how Spinoza could think that an "adequate knowledge of the [NS: formal] essence of things" could proceed "from an adequate idea of the formal essence of certain attributes" (IIp4os2, emphasis added).

Leibniz's way out of Della Rocca's dilemma suggests one way in which Spinoza could reconcile his apparent commitment to a plurality of attributes and modes with his rationalism. Like Leibniz, Spinoza could distinguish between two senses in which relations might be grounded, namely, ontologically and semantically. $\mathrm{He}$ could then maintain that any relation of co-existence holding between two attributes or modes must be ontologically grounded in minds-and in particular in the divine intellect. And, indeed, in a rare instance in which Spinoza directly addresses the ontology of relations, he tells us that relations "are in our understanding and not in Nature," that, they are "entia rationis," not "entia realia." ${ }^{8}$ If he were to follow Leibniz's lead, he could thus agree with Leibniz that if no mind were to relate two entities, there would be no relations between them, including no relation of co-existence, since relations are on this account ontologically mind-dependent.

Nonetheless he could also maintain that the co-existence of two attributes or modes may be semantically grounded in the relevant attributes or modes themselves. In that case, he could also agree with Leibniz that even if we were to bracket the contributions of minds, and therefore the existence of mind-dependent relations, it could nonetheless still be true that more than one mode, and more than one attribute, exist. That is to say, Spinoza could, like Leibniz, take a nominalist position with respect to the metaphysics of relations, while still insisting that nominalism is perfectly consistent with the objectivity of relational truths, statements, and propositions. ${ }^{29}$

28. See the first full paragraph of KV I, x (Shirley 2002: 59). For a helpful discussion of entia rationis in Spinoza, see Karolina Hübner (in press).

29. The distinction drawn here between ontological grounds and semantic grounds incidentally points, I think, to a possible way of understanding Spinoza's seemingly two-faced attitude towards the status of attributes. For Spinoza might think that attributes are ontologically mind-dependent and yet still maintain that truths about attributes are semantically, mind-independently grounded. A fuller discussion of this topic, however, will have to wait for another occasion. 
It is perhaps worth noting that in following Leibniz's lead, Spinoza might even be thought to have at least one advantage over Leibniz himself. For, as we saw earlier, Leibniz felt compelled, for largely theodician reasons, to offer a fairly elaborate and subtle account of the rational or teleological grounds for the existence of particular entities, including finite substances, appetites and perceptions. Spinoza's own account is, I think, in its own way, no less elaborate and subtle. As I read him at least, he wishes to distinguish between the possible teleological grounds of divine and creaturely activity, to deny that God acts for the sake of ends, but grant that creatures act for the sake of self-preservation (McDonough 20II). But, however one works out the details of Spinoza's account, this much at least should be clear: in squaring his metaphysics with the PSR, Spinoza has at least one less hurdle to jump than does Leibniz. For at the end of the day, Spinoza, insofar as he is a necessitarian, can uphold the PSR without having to show how teleological grounds may be less than necessary or necessitating. In following Leibniz's way out, Spinoza thus needn't worry about drawing Leibniz's difficult distinction between absolute and moral necessity, or insisting on there being reasons that incline without necessitating.

\subsection{A Second Way Out: Degrees of Existence}

Is there a better way out of Della Rocca's dilemma for Spinoza? Della Rocca suggests that the answer is "yes" and "yes," that is, he suggests that Spinoza actually has two promising responses to the dilemma he presents. The first of those responses turns centrally on the assumption that, for Spinoza, existence is not, as Della Rocca puts it, "an either-or matter" but "rather existence comes in degrees" (20I 2a: I 59). That suggestion is fleshed out by two related theses. First, that intelligibility comes in degrees-things can be more or less intelligible-and second, that degree of existence co-varies with degree of intelligibility. For Della Rocca's Spinoza, some beings exist more and some beings exist less, and those that exist more are more intelligible, and those that exist less are less intelligible.

Armed with the notion of degrees of existence, Della Rocca argues Spinoza can brave not just one but both horns of his rationalist dilemma. He can brave the first horn by accepting a limited or diminished plurality or multiplicity. Thus Della Rocca suggests that Spinoza "denies that there is a multiplicity of states and relations. But this denial is qualified: while there is no multiplicity, no states, and no relations that fully exist, there can be such things as long as they exist to a lesser degree" (20 2: I60). But Della Rocca's Spinoza isn't done. He can also, according to Della Rocca, brave the second horn by upholding a restricted or modified version of the PSR. Thus Della Rocca adds that Spinoza "denies the PSR by allowing for violations of it. But these violations do not fully exist and so they are not in conflict with the modified PSR which allows for degrees of intelligibility and degrees of existence" (201 2a: I60). Armed with degrees of existence, Della Rocca's 
Spinoza can thus both deny that there is a multiplicity of fully existing states and relations and uphold a modified PSR insofar as everything has a reason in proportion to its degree of existence.

While one can hardly fail to admire the ingenuity of Della Rocca's first response to his own rationalist dilemma, I'd like to briefly suggest two reasons for thinking that it is a less plausible route for Spinoza to follow than is Leibniz's. First, in spite of the connections drawn to intelligibility, I find the notion of degrees of existence very mysterious. And this in spite of the fact that I think the notion of degrees of being is both coherent and historically well founded. Philosophers from at least Augustine to Leibniz have thought that creatures could be arranged in an ontological hierarchy according to the degree of their being, with degrees of being being correlated in particular with degrees of goodness and perfection..$^{\circ} \mathrm{Good}$ angels were thus held to sit near the top of a hierarchy, with an extremely high degree of being and goodness, humans roughly in the middle being neither extremely elevated nor extremely low, and sin itself, understood as a privation of both being and goodness, marking the lowest limit of the great chain of being. A commitment to degrees of being, however, is not equivalent to the view that existence is not "an either-or matter." For on the traditional picture, things still either exist or don't exist, even though things that do exist can exist with varying degrees of being. Existence on the once standard account might be likened to a lamp on a dimmer switch: the lamp may be brighter or dimmer, but it has to be either on or off, and its having any degree of brightness presupposes that it is on. The traditional picture thus needn't maintain, what seems untenable to my ears, namely that somethingsay, an angel, a human, or a dog-might exist but not really or fully exist.

Second, there would seem to be no direct textual evidence for Spinoza's accepting the idea that there are degrees of existence rather than simply degrees of being. Della Rocca suggests that Spinoza's commitment to degrees of existence might be inferred from Spinoza's willingness to equate existence and intelligibility (20I 2a: I6I). Della Rocca thus argues, first, that, for Spinoza, God's existence just is his essence (Ip2o), but God's essence just is God's being conceived through itself (Idef 3 , Idef6), so as a consequence God's existence just is God's "being intelligible through itself." Della Rocca then argues, second, that Spinoza's naturalism, together with the PSR, dictates that the same story must apply, mutatis mutandis, to finite beings so that "the existence of things in general is just their conceivability or intelligibility" (20I 2a: I6I). In short, Della Rocca thus suggests that-for God and creatures alike-since existence is identical to intelligibility, and intelligibility comes in degrees, existence itself must also come in degrees, so that existence itself is not, after all, an "an either-or matter."

30. For a classic discussion of the "The Great Chain of Being," see Arthur O. Lovejoy (I936). For discussion of the relationship between being and goodness, see the essays in MacDonald (I99I). 
Although one might question whether Spinoza's naturalism really commits him to treating God and creatures on a par, the really heavy lifting of Della Rocca's argument is, I think, performed in its first part. It is therefore significant that none of the passages in the first part of Della Rocca's argument seem to require us to interpret Spinoza as upholding the novel and radical view that existence comes in degrees rather than the more traditional view that being-but not existence -comes in degrees. Indeed, all of the passages cited by Della Rocca in support of the first part of his argument would seem to simply echo traditional positions upheld by proponents of the view that being-but-not-existence comes in degrees. Thus, to be more specific, Spinoza's assertion at Ipzo that God's “existence and his essence are one and the same" would seem to simply affirm the view, widely held since at least Aquinas, that God's "essence is his existence itself" (Aquinas 2004: 89). Likewise, Spinoza's insistence at Idef 3 that "By substance I understand what is in itself and is conceived through itself, that is, that whose concept does not require the concept of another thing, from which it must be formed" would seem to simply echo the historically common view that the concept of God does not presuppose the concept of any other thing (Aquinas 2004: 89-90; cf. Descartes I994: I, 5I). Finally, Spinoza's assertion at Idef6 that "By God I understand a being absolutely infinite, that is, a substance consisting of an infinity of attributes, of which each one expresses an eternal and infinite essence" would seem to simply affirm, in Spinozistic terms, the traditional view that God must have all possible perfections either actually or eminently (Aquinas I98I: I.q4). Given that all of these passages admit of traditional rather than radical readings, I think they offer us no compelling reason for supposing that Spinoza meant to uphold the doctrine that existence rather than being comes in degrees. But if Spinoza means to simply uphold the traditional view that being, but not existence, comes in degrees then he can't escape Della Rocca's dilemma either by maintaining that no fully existing things violate the PSR or by introducing a modified version of the PSR that demands that things be intelligible only to the extent that they exist.

It might be replied that, even if all that is correct, Spinoza could still follow the spirit of Della Rocca's proposal by maintaining that things are intelligible in proportion to their degree of being. It might be suggested, for example, that my desk, my dog, and my doorman all exist and are all to some degree unintelligible brute things or facts, but that they are nonetheless no threat to a modified PSR that demands intelligibility only in proportion to degree of being. Such a maneuver, however, should seem unsatisfying for at least two reasons. First, it is not at all obvious that we should expect degrees of being and degrees of intelligibility to march in step. Superlatives are easy to attribute to God, so perhaps God will mark the upper end of both scales. It's not clear, however, that we should think that the existence of, say, an amoeba is necessarily more of a brute fact than say the existence of my dog, although presumably my dog will be assigned a higher degree of 
goodness and perfection, and therefore a higher degree of being than any amoeba. Second, it's not clear how much of the spirit of the PSR would be preserved by the proposed degrees-of-being-PSR. Perhaps the easiest way to feel the relevant worry is to recognize that the opponent of the PSR (if the previous concern is set aside) might in fact look quite favorably upon the proposed degrees-of-being-PSR. After all, it was commonly accepted that God alone could possibly have the highest degree of being and that all other things must have a less than full or maximum degree of being. If that's right, however, the proposed degrees-of-being-PSR would imply that every creature is to some degree unintelligible, that every being, perhaps other than God, must represent a brute fact, that is, must represent a violation of the full-blooded-PSR itself. What more could a reasonable opponent of the PSR possibly want? Spinoza, it seems to me, would surely be better off following Leibniz's lead than claiming such a hollow victory for rationalism.

\subsection{A Third Way Out: Radical Monism}

Della Rocca's second response turns centrally on the idea of there being different perspectives on the world, some more true or accurate than others. On some of those perspectives, there will be things that are not fully intelligible and do not fully exist. According to those perspectives, the PSR will be violated, but only to a degree. Nonetheless, given Spinoza's rationalism, there should be one perspective according to which the PSR is not violated in the least, and that perspective will be the most accurate as it will reflect things as they fully exist. If Della Rocca is right that the PSR cannot be reconciled with the co-existence of different attributes and modes, then it will follow that, from the truest perspective, there are no attributes or modes. The truest perspective simply is radical monism. The idea that there are less accurate perspectives that allow us to see the world as being populated by less than fully existing attributes and modes is presumably intended to help us reconcile our commonsense views and everyday experiences with a rather shocking metaphysics. Allowing less than fully accurate perspectives that carve the world into more familiar ways of being is, as it were, supposed to help us stop worrying and learn to love the metaphysical bomb.

I think there are textual reasons, already noted at the beginning of section 4.I., for hesitating to attribute this response to Spinoza. ${ }^{3 \mathrm{I}}$ If Spinoza embraced radical monism, then all his talk of infinite attributes and modes would be, strictly speaking, false and many of his most cherished doctrines would be unintelligible from

3I. I think this is a point that Della Rocca is actually happy to acknowledge (see, in particular, his (20I2b). For a broader perspective see also Newlands (20IIa; 20IIb). Della Rocca means to suggest, I believe, that the philosophically strongest strands in Spinoza's system point towards a radical monist solution, even if the bulk of his texts indicate that Spinoza himself took his system to be consistent with a rich plurality of modes and attributes. 
the most accurate perspective on the world. Della Rocca can, of course, marshal some texts that might seem to hint at Spinoza's embrace of radical monism. Della Rocca suggests, for example, that Spinoza's dictum, stated in Letter 50, that "determination is negation" is meant to imply that "individuals, insofar as they are passive, are nothing" (Spinoza I995: Letter 50). Likewise, Della Rocca sees intimations of Spinoza's commitment to radical monism in his claim, made in the context of a discussion of Adam's sinning in Letter I9, that "privation can be said only in relation to our intellect, not in relation to God's" (Spinoza I995: Letter I9). Such evidence, however, seems to me at best more obscure and less considered, than the relatively straightforward passages such as those in Ipros. While it might be possible to see insinuations of radical monism in carefully culled passages from Spinoza's letters and lesser texts, it is much easier, I think, to see a full-blooded commitment to plurality in Spinoza's carefully expressed declarations from his magnum opus such as (to repeat) that "a being absolutely infinite must be defined as a being that consists of infinite attributes," and that "since the divine nature has absolutely infinite attributes ... from its necessity there must follow infinitely many things in infinite modes."

Setting textual interpretation aside, however, there is, I think, an even deeper, conceptual problem with the radical monism route as presented by Della Rocca. For the combination of radical monism, multiple perspectives, and the PSR offered by Della Rocca's second way out seems to me to be itself fraught with paradox. Radical monism insists that, strictly speaking, there is no qualitative variety whatsoever. But how then could there be different perspectives-even false perspectives-on reality? Aren't different perspectives themselves a kind of variety, and thus shouldn't they be ruled out if radical monism is true? (See also Newlands 20 I Ib: I I 4 and Joachim I90I: II2.) Likewise, the PSR implies that if there are a variety of perspectives on the world, even a variety of less than fully accurate perspectives, there must be some reason for those perspectives. But what, if radical monism is true, could possibly be the reason for a variety of perspectives? Della Rocca's second way out thus seems to face its own dilemma, a dilemma that seems to me at least as potent as the dilemma it is supposed to solve. The rationalist who embraces the PSR must either allow that there are ungrounded perspectives on reality, thus abandoning the PSR, or she must deny, what seems undeniably true, that reality at least appears to contain a rich variety of things and properties. Better again for Spinoza to follow Leibniz's lead than to try to solve one apparent paradox by appeal to another.

\section{Conclusion}

The direct aim of this paper has been to argue that rationalists, including Leibniz and Spinoza, needn't choose between radical monism and the Principle of Sufficient 
Reason. Provided they tread carefully, they may maintain that relations, including the relation of co-existence, are both ontologically and semantically grounded. It was argued that Leibniz shows us one interesting way of doing this, suggesting that relations might be ontologically mind-dependent, but nonetheless semantically, or truth-makingly mind-independent. It was further argued that Leibniz's way of reconciling the PSR with multiplicity is also available to Spinoza, and indeed that it fits better with his texts and philosophical system than the more radical versions offered on Spinoza's behalf by Della Rocca.

These historical considerations, however, might be thought to support a less direct aim as well. The notion of grounding has recently enjoyed a great deal of attention, and has been explicitly touted as a return to an older way of doing metaphysics, a way that has as its forefathers Plato and Aristotle, rather than Carnap and Quine (see, for example, Schaffer 2009). In many instances, however, the notion of grounding has been developed on the assumption that grounding, or dependence, or holding in virtue of, must be wholly univocal, not admitting of different species. From a historical perspective, however, that assumption seems dubious. In thinking through the views of Leibniz and Spinoza, we've had occasion to distinguish at least three different kinds of dependence relations, namely, ontological, semantic, and teleological. To be sure, they have much in common, and it may well turn out that they share in particular some significant formal features. But even if that is so, it may nonetheless be helpful and illuminating to distinguish between different kinds of grounding relations. For, as we have seen above, it may well be the case that a given set of facts might be grounded in other facts in a variety of different ways.

\section{Acknowledgements}

Earlier versions of this paper were presented at Dalhousie University, MIT, Syracuse University, and the University of Toronto. I would like to thank participants at those events for their helpful feedback. I am also especially grateful for helpful discussions, comments and suggestions from Selim Berker, Michael Della Rocca, Brian Embry, Lauren Kopajtic, Samuel Levey, Kris McDaniels, Samuel Newlands, Marleen Rozemond, Kara Richardson, and two anonymous referees for this journal.

\section{Abbreviations}

A = Gottfried Wilhelm Leibniz (1923-). Gottfried Wilhelm Leibniz: Sämtliche Schriften und Briefe. Deutsche Akademie der Wissenschaften. Akademie-Verlag (Ed.). Cited by series, volume, and page. 
AG = Gottfried Wilhelm Leibniz (1989). Philosophical Essays (Roger Ariew \& Daniel Garber Eds. and Trans.). Hackett.

Ethics = Benedictus de Spinoza (I985). The Ethics. In Edwin Curley (Ed. And Trans), The Collected Works of Spinoza (Vol. I). Princeton University Press.

$\mathrm{G}=$ Gottfried Wilhelm Leibniz (I 875-I890). Die Philosophische Schriften von Gottfried Wilhelm Leibniz (Carl I. Gerhardt, Ed.). Weidmann. Reprinted Olms, I960. Cited by volume and page.

$\mathrm{H}=$ Gottfried Wilhelm Leibniz (I985). Theodicy (E.M. Huggard Ed. and Trans.). Open Court.

KV = Benedictus de Spinoza (2002). Korte Verhandeling van God, de Mensch, en deszelfs Welstand. In Samuel Shirley (Ed. and Trans.), The Complete Works of Spinoza. Hackett.

LDC = Gottfried Wilhelm Leibniz. (2007). The Leibniz-Des Bosses Correspondence (Brandon Look \& Donald Rutherford, Eds. and Trans.). Yale University Press.

LH = Gottfried Wilhelm Leibniz. (г 889). Die Leibniz-Handschriften der Königlichen Öffentlichen Bibliothek zu Hanover (Eduard Bodemann, Ed.). Hahn. Reprinted Olms, I966. Cited by Bodemann's numbering and page.

\section{References}

Adams, Marilyn McCord (I987). William Ockham (Vol. I). Notre Dame University Press. Adams, Robert (1994). Leibniz: Determinist, Theist, Idealist. Oxford University Press.

Aquinas, Thomas (I 882- ). Opera Omnia. Ed. Leonine Commission. Commissio Leonina. Reference is to work and relevant section.

Aquinas, Thomas (I98I). Summa Theologica. Trans. Fathers of the English Dominican Province. Christian Classics. Reference is to part and question.

Aquinas, Thomas (2004). Aquinas on Being and Essence: A Translation and Interpretation. Ed. and trans. Joseph Bobik. University of Notre Dame Press. Citation is to paragraph number. Auriol, Peter (I952-56). Scriptum super primum sententiarum (Vols. I-2). Ed. Eligius Buytaert. Franciscan Institute. Cited by Distinctio.

Bennett, Jonathan (I984). A Study of Spinoza's Ethics. Hackett.

Bennett, Jonathan (200I). Learning From Six Philosophers (Vol. I). Oxford University Press.

Bradley, Francis H. (I899). Appearance and Reality. The Macmillian Company.

Clatterbaugh, Kenneth (I973). Leibniz's Doctrine of Individual Accidents. Studia Leibnitiana, Sonderheft 4.

Correia, Fabrice (2010). Grounding and Truth-Functions. Logique et Analyse, 53, 25 I-79.

Correia, Fabrice, and Benjamin Schnieder (20I2). Grounding: An Opinionated Introduction. In Fabrice Correia and Benjamin Schnieder (Eds.), Metaphysical Grounding, Understanding the Structure of Reality (I-36). Cambridge University Press.

Cover, Jan A. (2004). Review of Leibniz on Purely Extrinsic Denominations by Dennis Plaisted. The Leibniz Review, I4, 99-108.

Cover, Jan A. and John O'Leary-Hawthorne (1999). Substance and Individuation in Leibniz. Cambridge University Press.

Della Rocca, Michael (2008a). Rationalism Run Amok: Representation and the Reality of 
Affects in Spinoza. In Charles Huenemann (Ed.), Interpreting Spinoza: Critical Essays (26-52). Cambridge University Press.

Della Rocca, Michael (2008b). Spinoza. Routledge.

Della Rocca, Michael (2010). PSR. The Philosophers' Imprint, Io(7), I-I3.

Della Rocca, Michael (20I 2a). Violations of the Principle of Sufficient Reason in Leibniz and Spinoza. In Fabrice Correia and Benjamin Schnieder (Eds.), Metaphysical Grounding, Understanding the Structure of Reality (I39-I64). Cambridge University Press.

Della Rocca, Michael (20I2b). Rationalism, Idealism, Monism, and Beyond. In Eckart Föster and Yitzhak Y. Melamed (Eds.), Spinoza and German Idealism (7-26). Cambridge University Press.

Descartes, René (I994). Principles of Philosophy. In John Cottingham, Robert Stoothof, and Dugald Murdoch (Eds. and Trans.), The Philosophical Writings of Descartes (Vol. I). Cambridge University Press. Cited by part and section.

Fine, Kit (2010). Some Puzzles of Ground. Notre Dame Journal of Formal Logic, $5 \mathrm{I}(\mathrm{I})$, 97-II 8.

Fine, Kit (20I2). Guide to Ground. In Fabrice Correia and Benjamin Schnieder (Eds.), Metaphysical Grounding, Understanding the Structure of Reality (37-80). Cambridge University Press.

Friedman, Russell L. (2009). Peter Auriol. In Edward N. Zalta (Ed.), The Stanford Encyclopedia of Philosophy (Fall 2009 Edition). Retrieved from http://plato.stanford.edu/ archives/fall2009/entries/auriol/.

Henninger, Mark G. (I989). Relations: Medieval Theories I250-I325. Oxford University Press.

Hintikka, Jaakko (I972). Leibniz on Plenitude, Relations and the 'Reign of Law'. In Harry Frankfurt (Ed.), Leibniz: A Collection of Critical Essays (I 55-I90). Doubleday.

Hübner, Karolina (in press). Spinoza on Essences, Universals and Beings of Reason. Pacific Philosophical Quarterly.

Hume, David ( 1980$)$. Dialogues Concerning Natural Religion ( ${ }^{\text {nd }}$ ed.). Hackett.

Ishiguro, Hidé (I990). Leibniz's Theory of the Ideality of Relations. In Harry Frankfurt (Ed.), Leibniz: A Collection of Critical Essays (I9I-2I3). Doubleday.

Jauernig, Anja (2010). Disentangling Leibniz's View on Relations and Extrinsic Denominations, Journal of the History of Philosophy, 48(2), I7I-205.

Jenkins, Carrie (20II). Is Metaphysical Dependence Irreflexive? The Monist, 94(2), 267276.

Joachim, Harold (I90I). A Study of the Ethics of Spinoza: Ethica Ordine Geometrico Demonstrata. Clarendon Press.

Kulstad, Mark (I980). A Closer Look at Leibniz's Alleged Reduction of Relations. Southern Journal of Philosophy, I 8(4), 4I7-32.

Lovejoy, Arthur O. (1936). The Great Chain of Being: A Study of the History of an Idea. Harvard University Press.

MacDonald, Scott (Ed.) (I99I). Being and Goodness: The Concept of Good in Metaphysics and Philosophical Theology. Cornell University Press.

Mates, Benson (1986). The Philosophy of Leibniz: Metaphysics and Language. Oxford University Press.

McCullough, Laurence B. (I996). Leibniz on Individuals and Individuation: The Persistence of Premodern Ideas in Modern Philosophy. Kluwer. 
McDonough, Jeffrey (2007). Leibniz: Creation and Conservation and Concurrence. Leibniz Review, I7, 3 I-60.

McDonough, Jeffrey (20II). The Heyday of Teleology and Early Modern Philosophy. In John Carriero (Ed.), Early Modern Philosophy Reconsidered: Essays in Honor of Paul Hoffman (Midwest Studies in Philosophy 35), I79-204.

Melamed, Yitzhak Y. (20I2). Why Spinoza is Not an Eleatic Monist (Or Why Diversity Exists). In Philip Goff (Ed.), Spinoza on Monism (206-22). Palgrave.

Mugnai, Massimo (1992). Leibniz' Theory of Relations. Franz Steiner Verlag.

Mugnai, Massimo (2010). Leibniz and 'Bradley's Regress'. The Leibniz Review, 20, I-I 2.

Mugnai, Massimo (20I2). Leibniz's Ontology of Relations: A Last Word? Oxford Studies in Early Modern Philosophy, 6, I7 I-208.

Newlands, Samuel (20IIa). Hegel's Idealist Reading of Spinoza. Philosophy Compass, 6(2), 100-108.

Newlands, Samuel (20I Ib). More Recent Idealist Readings of Spinoza. Philosophy Compass, 6(2), I09-I I9.

Ockham, William (I967-I986). Opera theologica, (Vols. I-IO). The Franciscan Institute. Cited by volume and page.

Plaisted, Dennis (2002). Leibniz on Purely Extrinsic Denominations. University of Rochester Press.

Rescher, Nicholas (I98I). Leibniz on Intermonadic Relations. In G. H. R. Parkinson (Ed.), Truth, Knowledge and Reality: Inquiries into the Foundations of Seventeenth-Century Rationalism (Studia Leibnitiana, Sonderheft 9). Reprinted in Nicholas Rescher, Leibniz's Metaphysics of Nature: A Group of Essays (56-83). Reidel.

Rosen, Gideon (2010). Metaphysical Dependence: Grounding and Reduction. In Robert Hale and Aviv Hoffman (Eds.), Modality: Metaphysics, Logic, and Epistemology (ro936). Oxford University Press.

Russell, Bertrand (I900). A Critical Exposition of the Philosophy of Leibniz. G. Allen \& Unwin. Third impression, I949, references to this edition.

Schaffer, Jonathan (2009). On What Grounds What. In David Chalmers, David Manley, and Ryan Wasserman (Eds.), Metametaphysics: New Essays on the Foundations of Ontology (347-83). Oxford University Press.

Schaffer, Jonathan (20I2). Grounding, Transitivity, and Constrastivity. In Fabrice Correia and Benjamin Schnieder (Eds.), Metaphysical Grounding, Understanding the Structure of Reality (I22-I3 8). Cambridge University Press.

Scotus, John Duns (I950-). Opera Omnia. Vatican Polyglot Press. Cited by volume and page.

Spinoza, Benedictus de (I995). The Letters (Samuel Shirely, Trans.). Hackett. Cited by letter number.

Spinoza, Benedictus de (I985). The Collected Works of Spinoza (Edwin Curley, Ed. and Trans, Vol. I). Princeton University Press.

Whitcomb, Dennis (20I I). Grounding and Omniscience. Oxford Studies in Philosophy of Religion, 4, I73-200. 